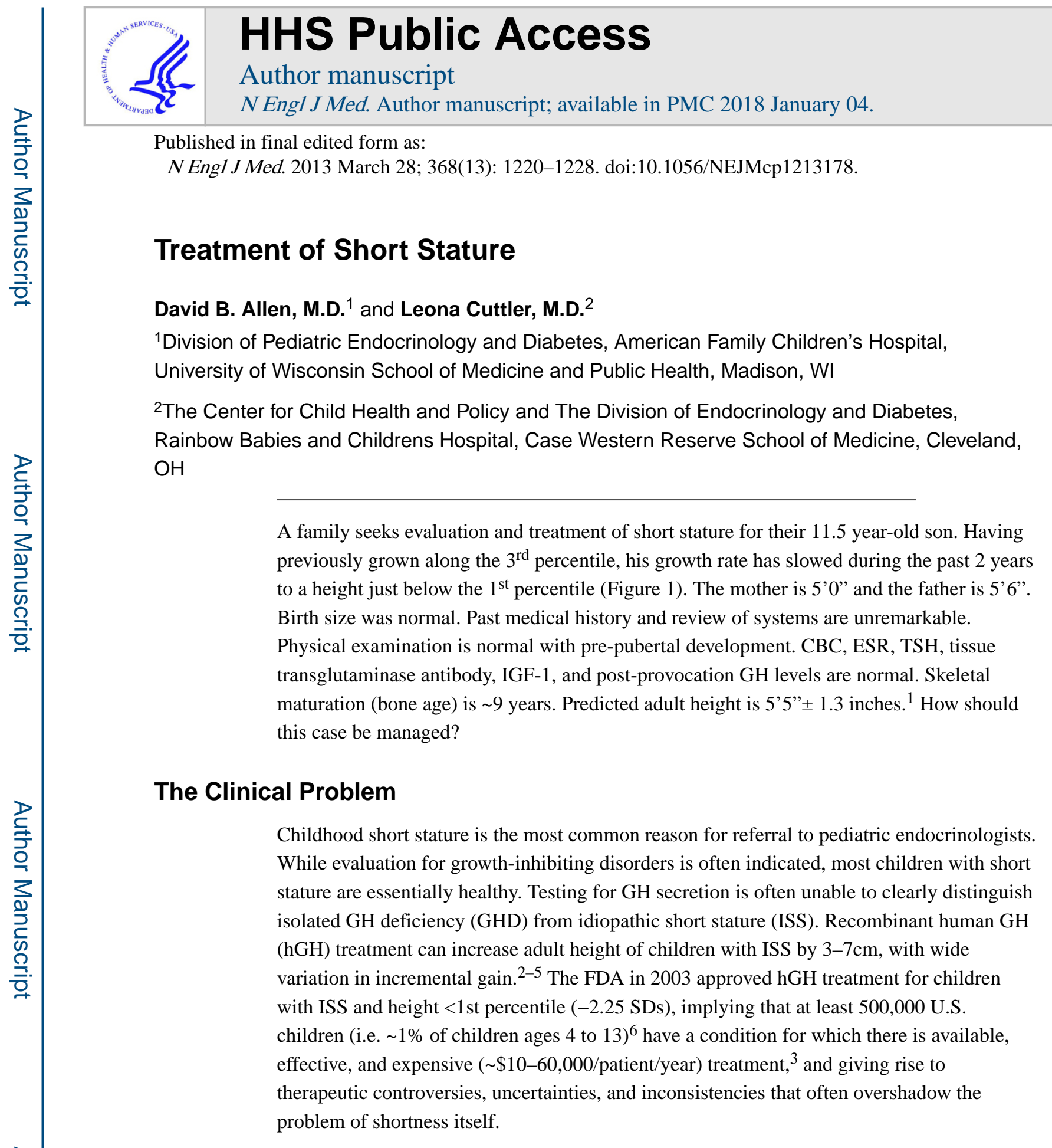

Correspondence to: David B. Allen, M.D., University of Wisconsin School of Medicine and Public Health, H4/448 CSC Department of Pediatrics, 600 Highland Avenue, Madison, WI 53792-4108, Phone: 6082635835, Fax: 6082657957, dballen@pediatrics.wisc.edu.

Disclosure:

No other potential conflict of interest relevant to this article was reported. Disclosure forms provided by the authors are available with the full text of this article at NEJM.org. 


\section{Strategies and Evidence}

\section{Evaluation}

Evaluation of children with short stature must consider many potential causes (Figure 2). ${ }^{7}$ While evaluation is needed to rule out disorders such as true growth hormone deficiency, Turner syndrome, hypothyroidism, or chronic diseases, the majority of children with short stature are ultimately diagnosed with ISS arising from normal variants such as familial short stature (FSS) and/or constitutional delay in growth and puberty (CDGP). In general, growth rate that is abnormally slow for chronological and skeletal age should prompt thorough examination and possible laboratory evaluation. Growth patterns differing markedly from mid-parental height (estimated by averaging parents' sex-specific height percentiles) are also of concern, although these estimates are less accurate when parental height percentiles are more disparate and also assume that parental height was not itself diminished by a growthrestricting condition. A family history of late pubertal onset and age of adult height attainment may suggest slowed "tempo" of growth and development (e.g. CDGP). A history of intrauterine growth restriction should also be assessed, as about $15 \%$ of such children remain short. ${ }^{7}$

Physical examination should assess for abnormal body proportions (e.g. increased upper-tolower body segment ratio - derived from comparisons of sitting and standing height suggesting bone dysplasia or Turner syndrome), characteristics suggesting genetic conditions (e.g. lymphedema or low posterior hairline for Turner syndrome, pulmonic stenosis murmur for Noonan syndrome), or findings (e.g. goiter) to suggest hypothyroidism. Disproportionately poor weight gain may suggest nutritional disturbance or chronic disease. Although children with true GHD may have classic physical findings such as increased subcutaneous fat, most present primarily with attenuated growth from infancy (congenital GHD) or later (acquired GHD).

FSS and/or CDGP are the most common explanations for short stature. However, when (1) height-for-age is less than 1st percentile, (2) growth rate is less than 10th percentile for skeletal age; (3) predicted adult height ${ }^{1}$ differs significantly from mid-parental height; and/or (4) body proportions are abnormal, laboratory evaluation is warranted.(Figure 2) Screening laboratory studies target potential hormonal (e.g. thyroid), renal (electrolytes, creatinine), inflammatory/immune (ESR, tissue transglutaminase antibody), and hematologic (CBC) disorders. Genetic testing for specific syndromes may be indicated by physical findings or simply a growth pattern and height projection differing significantly from the family. Assessment of the GH-IGF axis begins with a serum IGF-1 level, but, since levels rise rapidly with puberty onset, results must be interpreted relative to skeletal rather than chronological age. Normal IGF-1 for skeletal age excludes severe, but perhaps not less severe, forms of GHD. ${ }^{8}$ Testing GH levels following provocation with various agents is the classic method for assessing GHD, but the interpretation of results is complicated by variation in testing procedures and unclear sensitivity/specificity (and variation among countries) of cut-offs used for diagnosis. The diagnostic value of stimulated GH levels (especially $5-10 \mathrm{ng} / \mathrm{ml}$, with $>10 \mathrm{ng} / \mathrm{ml}$ a conventional threshold suggesting adequate $\mathrm{GH}$ 
secretion) is controversial. Moreover, relatively low GH levels during late childhood may return to normal after puberty begins ${ }^{9}$ or with sex-steroid priming. ${ }^{10}$

A low IGF-1 level and low provoked GH levels (e.g. $<5 \mathrm{ng} / \mathrm{ml}$ ) in a child with attenuated growth strongly suggests GHD; pituitary MRI can be helpful in such cases, since abnormal findings such as diminished pituitary size or ectopic/absent posterior pituitary enhancement further support this diagnosis. ${ }^{11}$ For the large majority of short children, however, history and examination are unrevealing, and tests yield equivocal or normal results. These children are generally considered to have non-GHD short stature - ISS or normal variants (i.e. FSS and/or CDGP, both of which are sometimes included under the umbrella of ISS). ${ }^{12}$

\section{Management}

Children with non-GHD short stature may receive markedly different recommendations that vary in complexity and costs and for which relative benefits and risks are uncertain.

Management decisions often evolve from primary care physicians' threshold for specialist consultation to rule out pathologic causes of shortness, pediatric endocrinologists' perspective about use of growth-promoting medications, insurance, ${ }^{13-16}$ and parents concerned that their child is "noticeably shorter than the other kids" or "teased because of his/her size." Their potentially valid concern - "my child is short and needs help to be taller"- ranges in meaning from "will s/he be disabled by short stature as an adult?" to "will s/he be disadvantaged in social and career success?"17 to "would s/he feel better if s/he were taller?"18

Once referred to endocrinologists, decisions regarding treatment depend on physician and family perspectives on: 1) whether short stature is a disorder or disability warranting medical treatment and, if so; 2) whether the therapeutic goal should be faster growth during childhood or a normal, increased, or maximum attainable adult height; 3 ) responsible use of resources, and concerns about long-term safety. ${ }^{15,19}$

\section{Management options for non-GH deficient short stature}

The rationale for treating childhood short stature includes increasing height and alleviating psychosocial disability while maintaining favorable risk/benefit and cost/benefit ratios. Selection among management options may therefore depend on the degree to which each meets these goals.

Observation and reassurance with no treatment (Figure $3 \mathrm{~A}$ )-Observation is a reasonable strategy for most children with FSS or CDGP. ${ }^{20}$ While a child may be teased or feel sad about being short, comparisons of non-GHD short children to taller peers ${ }^{21,22}$ or psychosocial assessment of short adults ${ }^{23}$ indicate that psychological stress can be ${ }^{22}$ but is not predictably ${ }^{21}$ related to stature. Further, increases in growth rate and height resulting from androgen ${ }^{24}$ or hGH treatment (including one single double-blind, placebo-controlled trial $)^{25}$ have not predictably improved psychosocial well-being, even when the surrogate measure of final height is increased. ${ }^{26,27}$ Without treatment, while shortness compared to peers may temporarily worsen in late childhood due to delayed puberty (Figure 3A), 
predicted adult height (and height eventually achieved) will likely approximate the low normal range target height consistent with parental heights.

Height-promoting treatment with hGH-FDA approval of hGH for children with ISS $^{28}$ implies that etiology of short stature - and GH secretory status - is not critical in decisions about whether such children should be treated. ${ }^{29}$ Data from randomized controlled trials, ${ }^{4}$ observational dose-response ${ }^{5}$ studies, and systematic reviews ${ }^{2}$ indicate that hGH therapy in children with ISS increases growth rate and mean adult height (by 3 to $7 \mathrm{~cm}$ or $\sim 1 \mathrm{~cm} /$ year of hGH treatment). ${ }^{2,4,5,12}$ The response is variable, influenced positively by baseline younger age, delay in skeletal maturation, ${ }^{4}$ and taller parents (and negatively by shorter parents). ${ }^{2}$ Subcutaneous, daily (superior to less frequent administration) ${ }^{30} \mathrm{hGH}$ is dosed at $0.2-0.375 \mathrm{mg} / \mathrm{kg} / \mathrm{week}$. Dose modulation may influence effect; dosages in the higher end of this range ${ }^{30,31}$ and titration of dosage to achieve high-normal IGF-1 levels ${ }^{32}$ lead to faster growth and perhaps to taller adult height ${ }^{33}$, although this has not been assessed in randomized trials. Doubling hGH dosage during puberty until epiphyseal closure, in one controlled trial, further increased near-final height.(Figure 3F) ${ }^{34}$ Treatment is typically continued until epiphyseal closure (Figure 3E) or to a height subjectively considered "satisfactory" by the child/family and physician. Alternatively, since most children with equivocal GH tests demonstrate normal endogenous GH secretion and sustained normal growth to normal height after onset of puberty, ${ }^{35}$ a 4-6 month trial off hGH (with reinstitution of therapy if growth slows abnormally) can be considered when signs of puberty are evident ${ }^{29}$ (Figure 3C) The effect of such an approach on adult height has not been examined in randomized trials.

Extensive clinical experience indicates that on-treatment risks of adverse effects from hGH are low (e.g. rare occurrences of intracranial hypertension, glucose intolerance, slipped capital femoral epiphysis). ${ }^{36}$ However, safety data from post-marketing surveillance studies likely underestimate risks associated with higher hGH dosages and changing patient risk factors (e.g. increased prevalence of obesity with higher risks of diabetes) and do not inform post-treatment metabolic or malignancy risks. ${ }^{37-39}$ A long-term follow-up study of GHD, ISS, and small-for-gestational-age individuals from France reported an increased post-hGH treatment standardized mortality ratio of $1.33,4^{40}$ assessment of cause -specific mortality identified higher risks of death attributable to bone cancer and circulatory system disorders in GH-treated persons, and increased risk with hGH dosage $>0.35 \mathrm{mg} / \mathrm{kg} /$ week. However, a similar surveillance study from Belgium, Netherlands, and Sweden did not confirm these findings. ${ }^{41}$ Additionally, hGH treatment for ISS is expensive, estimated at $\sim \$ 35,000$ $\$ 50,000$ per inch. ${ }^{3,42}$ Higher dose regimens and longer treatment duration increase costs (and may also increase risks). ${ }^{29}$ (Table 1)

Treatment to increase growth rate without hGH-Non-hGH growth-promoting therapies for short peri-pubertal boys include low-dose androgen therapy with either injectable testosterone or oral oxandrolone (e.g. $1.25-2.5 \mathrm{mg} /$ day). Both are relatively low in cost, and, though not FDA-approved for growth acceleration, increase growth rate by 3-5 $\mathrm{cm} /$ year for 1-3 years in controlled trials. ${ }^{24,43,44}$ To avoid accelerated estrogen-mediated epiphyseal maturation, oxandrolone (not aromatized to estrogen), is theoretically preferred 
over testosterone when skeletal age is < 11 years. Oxandrolone is usually discontinued after a documented rise in endogenous testosterone; long term follow up studies indicate that treatment is followed by normal pubertal growth and eventual attainment of an adult height equal to or slightly greater than ${ }^{43}$ pre-treatment predicted height. (Figure 3B) Extensive clinical experience indicates that risks of low-dose androgen treatment (e.g. adverse hepatic or lipid effects) are low. $24,43,44$

Aromatase inhibitors (which reduce estrogen production and delay skeletal maturation) have been used experimentally in boys to prolong pubertal growth and increase height, but are more expensive, have less growth-accelerating effect than androgens, and actual adult height gains ${ }^{45}$ have fallen short of prior $4-6 \mathrm{~cm}$ predictions. ${ }^{46}$ With concerns about potential adverse effects of estrogen deficiency during pubertal growth, including vertebral body deformities, ${ }^{45}$ they cannot be recommended for short stature treatment outside of investigative studies.

\section{Areas of Uncertainty}

Decisions regarding the treatment of non-GHD short stature are complicated by uncertainties about the morbidity of short stature, appropriate therapeutic goals, and determination of risk (and cost)-benefit ratios. The assumption that shortness is predictably associated with psychological distress is challenged by studies demonstrating only minor difficulties in behavioral adaptation and normal psychological function in short-statured children ${ }^{21,47}$ and adults. ${ }^{23}$ It is therefore unclear whether or how to include psychosocial factors in determining therapeutic objectives.

If treatment is instituted, should the goal be short-term growth acceleration or increased adult height? If the latter, should the aim be an adult height within the statistical normal range (e.g. $5^{\text {th }}$ percentile: $\sim 5$ ' $5^{\prime}$ ' for man, $\sim 5^{\prime}$ for woman), a height matching family heights, or a height as tall as safely possible? These different goals carry markedly different costs; the last $1-3 \%$ of potential height gain may increase total expenditure by $20 \% .{ }^{19}$ Without evidence that the surrogate measure of increased height improves patient well-being, ${ }^{25}$ different treatment strategies cannot be differentiated based on quality of life outcomes.

Finally, more data are needed to inform potential risks of long term hGH therapy. Given evidence supporting a role for the GH-IGF system in the pathogenesis of various cancers, ${ }^{47}$ more data (preferably from large international collaborative studies) are needed to better understand the existence and magnitude of any long-term disease risks associated with hGH use $\cdot 39,47$

\section{Guidelines}

Existing guidelines and consensus statements from professional societies (Growth Hormone Research Society, Pediatric Endocrine Society, European Society for Paediatric Endocrinology) on treatment of non-GHD short children ${ }^{12,48}$ review FDA guidelines, address issues of interpreting GH stimulation tests and IGF-I levels, outline possible hGH doses, describe hGH risks and possible benefits, and recommend aspects of treatment follow-up. However, they do not specify how to select among therapeutic options for short 
stature, the goals and cost-effectiveness of medical intervention, and on when/whether to discontinue treatment in cases in which it is initiated.

\section{Conclusions and recommendations}

The peri-pubertal boy described in the vignette is markedly short, but otherwise appears healthy. While his earlier life growth pattern and predicted height match that expected based on family heights, slowed growth rate and severity of short stature justify screening studies to rule out underlying disease or frank GHD. Normal findings on these tests support a diagnosis of ISS (FSS combined with, and exacerbated by, CDGP). Options for treatment of ISS should be discussed with the child and his parents, including observation and reassurance, hGH therapy, or shorter term androgen therapy. One reasonable strategy is observation, supported by the lack of good evidence linking short stature with psychological morbidity or demonstrating long term psychosocial benefit with growth-enhancing therapy, and the expectation for eventual achievement of adult height approximating mid-parental height. Alternatively, hGH treatment has been shown to increase growth rate and, to varying and albeit generally modest degrees ( 3 to $7 \mathrm{~cm}$ ), eventual adult height While hGH treatment has a strong safety record, it is costly, requires daily injections, and could potentially have remote adverse effects that are relevant to treatment decisions for an otherwise healthy child. ${ }^{49}$ A third option is low-dose, shorter-term oral oxandrolone treatment, which also stimulates growth, is given orally, has relatively low cost, but has no proven salutary effect on eventual attained height.

Whereas height augmentation treatment has a role in some cases of non GHD short stature, and in particular may benefit children with extreme, disabling short stature, benefits of treatment are uncertain for the vast number of otherwise healthy children with marginal shortness likely to reach relatively short but normal adult heights. Further, for those who are treated, appropriate treatment goals and optimal length of therapy remain controversial. Thus, for a child such as the one described in the vignette (who is currently just below the $1^{\text {st }}$ percentile for height, but whose projected height is in the lower end of the normal adult range) we would provide reassurance and recommend observation as a reasonable management option. hG is used, a goal of adult height within the normal range , rather than maximum attainable height is or If psychological distress is significant and intervention elected, short-term treatment with low-dose (and relatively low-cost) oxandrolone could be considered. If hGH is used, we would consider an appropriate treatment goal to be a height in the lower normal range (e.g. $\sim 5^{\text {th }}-10^{\text {th }}$ percentile for U.S. adults rather than maximal attainable height), taking into account both the costs of therapy and potential risks of prolonged or high dose therapy.

\section{Acknowledgments}

Dr. Allen reports receiving grant support through his institution from Novo-Nordisk.

Supported in part by a grant from NIH (LC) 


\section{References}

1. Zachmann MSB, Frank M, Frisch H, Prader A. Bayley-Pinneau, Roche-Wainer-Thissen, and Tanner height predictions in normal children and in patients with various pathologic conditions. The Journal of pediatrics. 1978; 93:749-53. [PubMed: 712475]

2. Deodati A, Cianfarani S. Impact of growth hormone therapy on adult height of children with idiopathic short stature: systematic review. BMJ. 2011; 342

3. Finkelstein BS, Imperiale TF, Speroff T, Marrero U, Radcliffe DJ, Cuttler L. Effect of growth hormone therapy on height in children with idiopathic short stature: a meta-analysis. Arch Pediatr Adolesc Med. 2002; 156:230-40. [PubMed: 11876666]

4. Leschek EW, Rose SR, Yanovski JA, et al. Effect of growth hormone treatment on adult height in peripubertal children with idiopathic short stature: a randomized, double-blind, placebo-controlled trial. The Journal of clinical endocrinology and metabolism. 2004; 89:3140-8. [PubMed: 15240584]

5. Wit JM, Rekers-Mombarg LT, Cutler GB, et al. Growth hormone (GH) treatment to final height in children with idiopathic short stature: evidence for a dose effect. The Journal of pediatrics. 2005; 146:45-53. [PubMed: 15644821]

6. statistics CfDC. 2010. http://www.childstats.gov/americaschildren/tables.asp

7. Nicol, L., Allen, DB., Czernichow, P., Zeitler, P. Normal growth and growth disorders. In: Kappy, M.Allen, DB., Geffner, M., editors. Pediatric Practice: Endocrinology. New York, NY: McGraw Hill; 2010. p. 23-76.

8. Consensus guidelines for the diagnosis and treatment of growth hormone $(\mathrm{GH})$ deficiency in childhood and adolescence: summary statement of the GH Research Society. GH Research Society. The Journal of clinical endocrinology and metabolism. 2000; 85:3990-3. [PubMed: 11095419]

9. Bourmelen M. Transient partial hGH deficiency in prepubertal children with delay of growth. Pediatr Res. 1979; 13:221-4. [PubMed: 471580]

10. Marin G, Domene HM, Barnes KM, Blackwell BJ, Cassorla FG, Cutler GB Jr. The effects of estrogen priming and puberty on the growth hormone response to standardized treadmill exercise and arginine-insulin in normal girls and boys. The Journal of clinical endocrinology and metabolism. 1994; 79:537-41. [PubMed: 8045974]

11. Maghnie M, Ghirardello S, Genovese E. Magnetic resonance imaging of the hypothalamuspituitary unit in children suspected of hypopituitarism: who, how and when to investigate. Journal of endocrinological investigation. 2004; 27:496-509. [PubMed: 15279086]

12. Cohen P, Rogol AD, Deal CL, et al. Consensus statement on the diagnosis and treatment of children with idiopathic short stature: a summary of the Growth Hormone Research Society, the Lawson Wilkins Pediatric Endocrine Society, and the European Society for Paediatric Endocrinology Workshop. The Journal of clinical endocrinology and metabolism. 2008; 93:42107. [PubMed: 18782877]

13. Cuttler L, Marinova D, Mercer MB, Connors A, Meehan R, Silvers JB. Patient, physician, and consumer drivers: referrals for short stature and access to specialty drugs. Medical care. 2009; 47:858-65. [PubMed: 19543124]

14. Cuttler L, Silvers JB, Singh J, et al. Short stature and growth hormone therapy. A national study of physician recommendation patterns. JAMA : the journal of the American Medical Association. 1996; 276:531-7. [PubMed: 8709401]

15. Silvers JB, Marinova D, Mercer MB, Connors A, Cuttler L. A national study of physician recommendations to initiate and discontinue growth hormone for short stature. Pediatrics. 2010; 126:468-76. [PubMed: 20805144]

16. Cuttler L, Silvers JB. Growth hormone and health policy. The Journal of clinical endocrinology and metabolism. 2010; 95:3149-53. [PubMed: 20427500]

17. Persico NPA, Silverman D. The effect of adolescent experience on labor market outcomes: the case of height. J Polit Econ. 2004; 112:1019-53.

18. Allen DB. Growth hormone therapy for short stature: is the benefit worth the burden? Pediatrics. 2006; 118:343-8. [PubMed: 16818584] 
19. Cuttler L, Silvers JB, Singh J, Tsai AC, Radcliffe D. Physician decisions to discontinue long-term medications using a two-stage framework: the case of growth hormone therapy. Medical care. 2005; 43:1185-93. [PubMed: 16299429]

20. Cuttler, L., Misra, M. Growth and Maturation. In: Jameson, JL., DeGroot, LJ., editors. Endocrinology: Adult and Pediatric. Philadelphia: Elsevier; 2010.

21. Sandberg DE, Bukowski WM, Fung CM, Noll RB. Height and social adjustment: are extremes a cause for concern and action? Pediatrics. 2004; 114:744-50. [PubMed: 15342848]

22. Geisler A, Lass N, Reinsch N, et al. Quality of life in children and adolescents with growth hormone deficiency: association with growth hormone treatment. Horm Res Paediatr. 2012; 78:5.

23. Ulph F, Betts P, Mulligan J, Stratford RJ. Personality functioning: the influence of stature. Archives of disease in childhood. 2004; 89:17-21. [PubMed: 14709494]

24. Wilson DM, McCauley E, Brown DR, Dudley R. Oxandrolone therapy in constitutionally delayed growth and puberty. Bio-Technology General Corporation Cooperative Study Group. Pediatrics. 1995; 96:1095-100. [PubMed: 7491227]

25. Ross JL, Sandberg DE, Rose SR, et al. Psychological Adaptation in Children with Idiopathic Short Stature Treated with Growth Hormone or Placebo. Journal of Clinical Endocrinology \& Metabolism. 2004; 89:4873-8. [PubMed: 15472178]

26. Lagrou K, Froidecoeur C, Verlinde F, et al. Psychosocial functioning, self-perception and body image and their auxologic correlates in growth hormone and oestrogen-treated young adult women with Turner syndrome. Hormone research. 2006; 66:277-84. [PubMed: 16946621]

27. Visser-van Balen H, Geenen R, Kamp GA, Huisman J, Wit JM, Sinnema G. Long-term psychosocial consequences of hormone treatment for short stature. Acta paediatrica (Oslo, Norway: 1992). 2007; 96:715-9.

28. DG O. Approval letter: Humatropen injection device and draft package insert. Food and Drug Administration Center for Drug Evaluation Research Web site; 2003. Available at:http:// www.fda.gov/cder/foi/appletter/2003/19640se1-0331tr.pdf

29. Allen DB, Fost N. hGH for short stature: ethical issues raised by expanded access. The Journal of pediatrics. 2004; 144:648-52. [PubMed: 15127004]

30. Grimberg A, Cohen P. Optimizing growth hormone therapy in children. Hormone research. 1997; 48(Suppl 5):11-5.

31. Frasier SD, Costin G, Lippe BM, Aceto T Jr, Bunger PF. A dose-response curve for human growth hormone. The Journal of clinical endocrinology and metabolism. 1981; 53:1213-7. [PubMed: 7298800]

32. Cohen P, Bright GM, Rogol AD, Kappelgaard AM, Rosenfeld RG. Effects of dose and gender on the growth and growth factor response to $\mathrm{GH}$ in GH-deficient children: implications for efficacy and safety. The Journal of clinical endocrinology and metabolism. 2002; 87:90-8. [PubMed: 11788629]

33. Blethen SL, Baptista J, Kuntze J, Foley T, LaFranchi S, Johanson A. Adult height in growth hormone (GH)-deficient children treated with biosynthetic GH. The Genentech Growth Study Group. The Journal of clinical endocrinology and metabolism. 1997; 82:418-20. [PubMed: 9024229]

34. Mauras N, Attie KM, Reiter EO, Saenger P, Baptista J. High dose recombinant human growth hormone $(\mathrm{GH})$ treatment of $\mathrm{GH}$-deficient patients in puberty increases near-final height: a randomized, multicenter trial. Genentech, Inc., Cooperative Study Group. The Journal of clinical endocrinology and metabolism. 2000; 85:3653-60. [PubMed: 11061518]

35. Tauber M, Moulin P, Pienkowski C, Jouret B, Rochiccioli P. Growth hormone (GH) retesting and auxological data in $131 \mathrm{GH}$-deficient patients after completion of treatment. The Journal of clinical endocrinology and metabolism. 1997; 82:352-6. [PubMed: 9024217]

36. Bell J, Parker KL, Swinford RD, Hoffman AR, Maneatis T, Lippe B. Long-term safety of recombinant human growth hormone in children. The Journal of clinical endocrinology and metabolism. 2010; 95:167-77. [PubMed: 19906787]

37. Cuttler L. Safety and efficacy of growth hormone treatment for idiopathic short stature. The Journal of clinical endocrinology and metabolism. 2005; 90:5502-4. [PubMed: 16148349] 
38. Child CJ, Zimmermann AG, Scott RS, Cutler GB Jr, Battelino T, Blum WF. Prevalence and incidence of diabetes mellitus in GH-treated children and adolescents: analysis from the GeNeSIS observational research program. The Journal of clinical endocrinology and metabolism. 2011; 96:E1025-34. [PubMed: 21490076]

39. Allen DB. Growth hormone post-marketing surveillance: safety, sales, and the unfinished task ahead. The Journal of clinical endocrinology and metabolism. 2010; 95:52-5. [PubMed: 20056808]

40. Carel JC, Ecosse E, Landier F, et al. Long-term mortality after recombinant growth hormone treatment for isolated growth hormone deficiency or childhood short stature: preliminary report of the French SAGhE study. The Journal of clinical endocrinology and metabolism. 2012; 97:416-25. [PubMed: 22238382]

41. Savendahl L, Maes M, Albertsson-Wikland K, et al. Long-term mortality and causes of death in isolated GHD, ISS, and SGA patients treated with recombinant growth hormone during childhood in Belgium, The Netherlands, and Sweden: preliminary report of 3 countries participating in the EU SAGhE study. The Journal of clinical endocrinology and metabolism. 2012; 97:E213-7. [PubMed: 22238393]

42. Lee JM, Davis MM, Clark SJ, Hofer TP, Kemper AR. Estimated cost-effectiveness of growth hormone therapy for idiopathic short stature. Arch Pediatr Adolesc Med. 2006; 160:263-9. [PubMed: 16520445]

43. Schroor EJ, van Weissenbruch MM, Knibbe P, Delemarre-van de Waal HA. The effect of prolonged administration of an anabolic steroid (oxandrolone) on growth in boys with constitutionally delayed growth and puberty. European journal of pediatrics. 1995; 154:953-7. [PubMed: 8801102]

44. Keenan BS, Richards GE, Ponder SW, Dallas JS, Nagamani M, Smith ER. Androgen-stimulated pubertal growth: the effects of testosterone and dihydrotestosterone on growth hormone and insulin-like growth factor-I in the treatment of short stature and delayed puberty. The Journal of clinical endocrinology and metabolism. 1993; 76:6.

45. Wit JM, Hero M, Nunez SB. Aromatase inhibitors in pediatrics. Nature Reviews - Endocrinology. 2012; 8:135.

46. Salehpoura S, Alipourc P, Razzaghy-Azarc M, et al. A Double-Blind, Placebo-Controlled Comparison of Letrozole to Oxandrolone Effects upon Growth and Puberty of Children with Constitutional Delay of Puberty and Idiopathic Short Stature. Horm Res Paediatr. 2010; 74:8.

47. Rosenfeld RG, Cohen P, Robison LL, et al. Long-term surveillance of growth hormone therapy. The Journal of clinical endocrinology and metabolism. 2012; 97:68-72. [PubMed: 22174422]

48. Wilson TA, Rose SR, Cohen P, et al. Update of guidelines for the use of growth hormone in children: the Lawson Wilkins Pediatric Endocrinology Society Drug and Therapeutics Committee. The Journal of pediatrics. 2003; 143:415-21. [PubMed: 14571209]

49. Allen DB. Clinical review: Lessons learned from the hGH era. The Journal of clinical endocrinology and metabolism. 2011; 96:3042-7. [PubMed: 21865374] 


\section{Take-home points}

Thorough evaluation of childhood short stature is warranted when height deficit is severe ( $<1$ st percentile), growth rate is abnormally slow ( $<10$ th percentile for skeletal age), predicted height differs significantly from mid-parental height, or body proportions are abnormal.

hGH treatment increases growth rate and modestly increases adult height, and has demonstrated safety in the short term, but is expensive and its long-term risk/benefit ratio for essentially healthy children remains uncertain.

Observation and reassurance is reasonable for most short children, given the lack of good evidence linking short stature with psychological morbidity or demonstrating long term psychosocial benefit with growth-enhancing therapy.

Short-term low-dose oral oxandrolone is an effective and relatively inexpensive option for growth acceleration, but has not been shown to increase adult height.

Existing evidence supports a conservative approach to managing short stature in opting for treatment over observation, and with regard to therapeutic goals when treatments are used. 


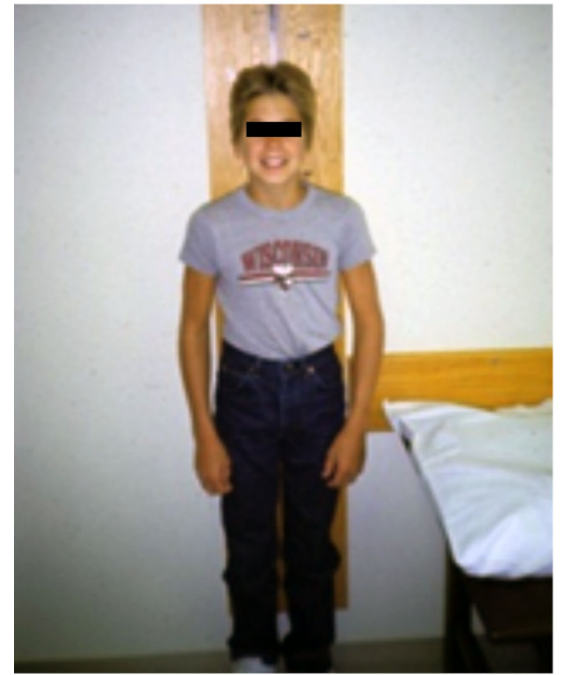

11.5 y.o. male

Height $1^{\text {st }}$ percentile

Skeletal age 9 years

Bayley-Pinneau predicted adult height $=65 \mathrm{in}^{*}$

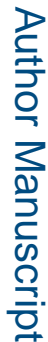

Mid-parental height 65 in

Figure 1.

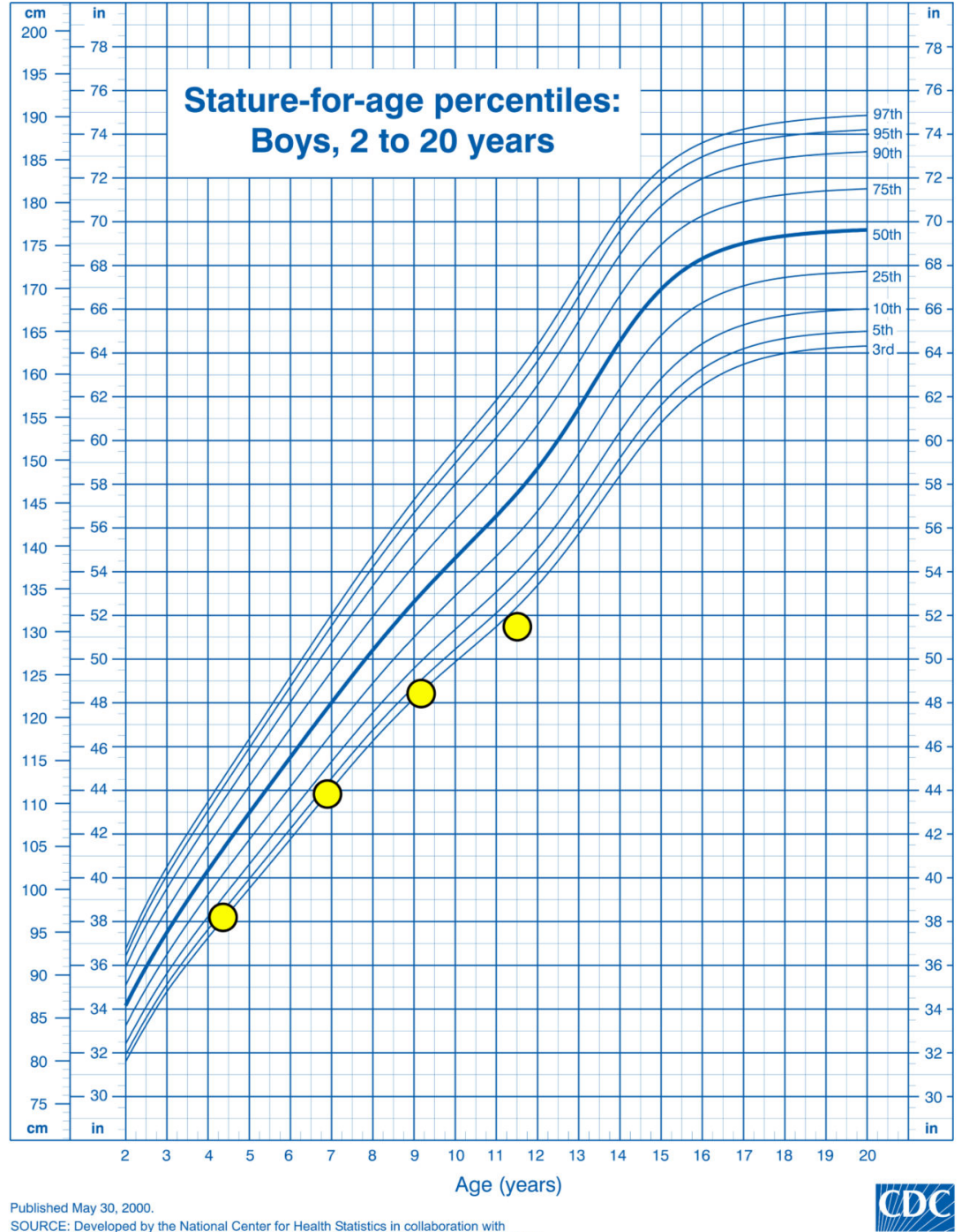

: Developed by the National Center for Health Statistics in collaboration with
the National Center for Chronic Disease Prevention and Health Promotion (2000).

Growth curve and clinical data of the patient. Predicted adult height (PAH) for observationalone approach calculated using Bayley-Pinneau method. ${ }^{1}$ 


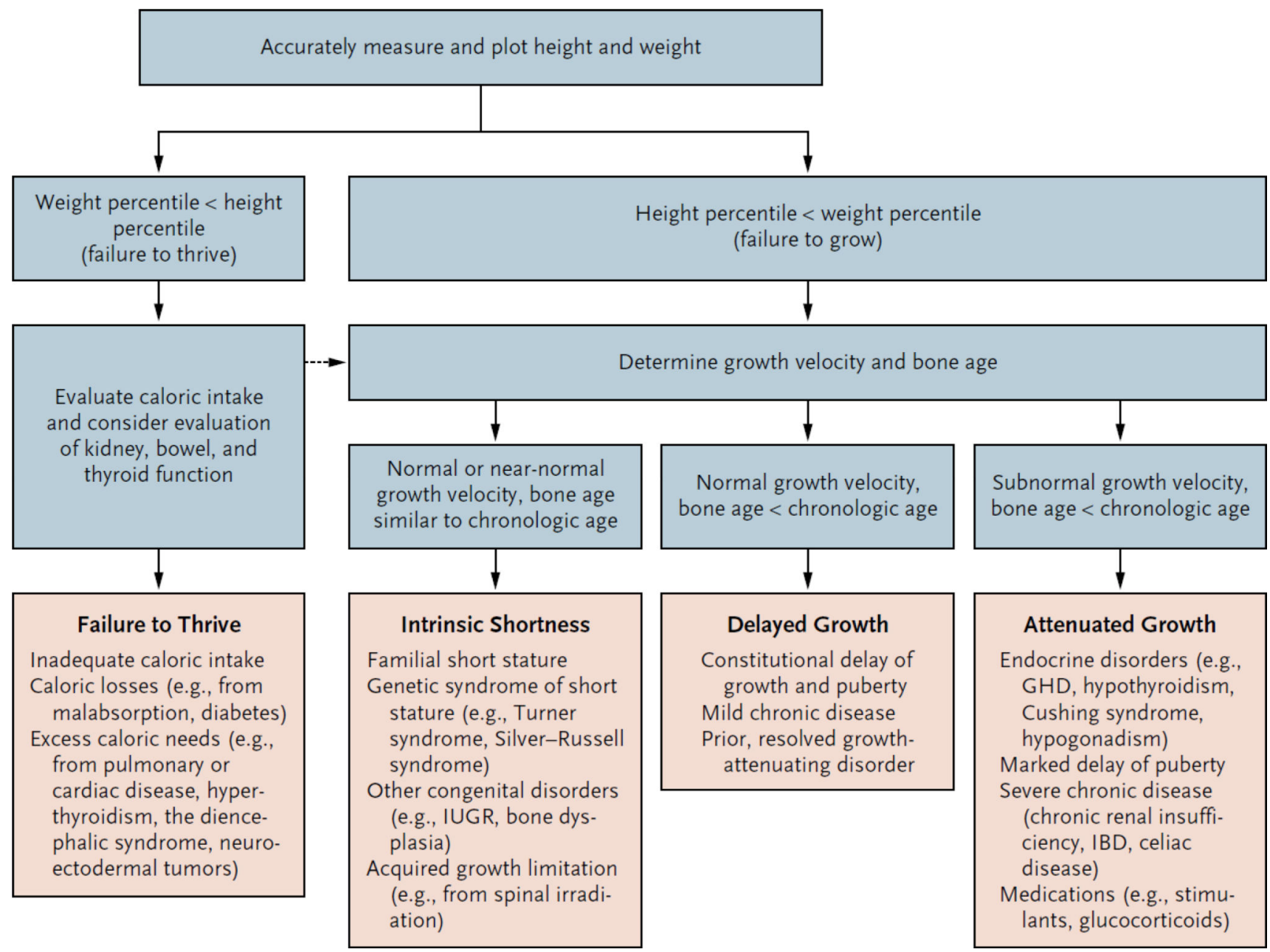

Figure 2.

Conceptual approach to the evaluation and differential diagnosis of worrisome growth and short stature. $\left(\right.$ adapted from ${ }^{7}$ ) Key: $*$ = downward crossing of percentiles, height $<3$ rd percentile, or height inappropriate for family, or abnormal body proportions; \%tile = growth curve percentile; $\mathrm{GV}=$ growth velocity; $\mathrm{BA}=$ bone age; $\mathrm{CA}=$ chronological age; $\mathrm{TS}=$ Turner syndrome; RSS = Russell Silver syndrome; IUGR = intrauterine growth restriction; $\mathrm{CDGP}=$ constitutional delay in growth and puberty; GHD = growth hormone deficiency; CS $=$ Cushing syndrome; $\mathrm{CRI}=$ chronic renal insufficiency; $\mathrm{IBD}=$ inflammatory bowel disease 


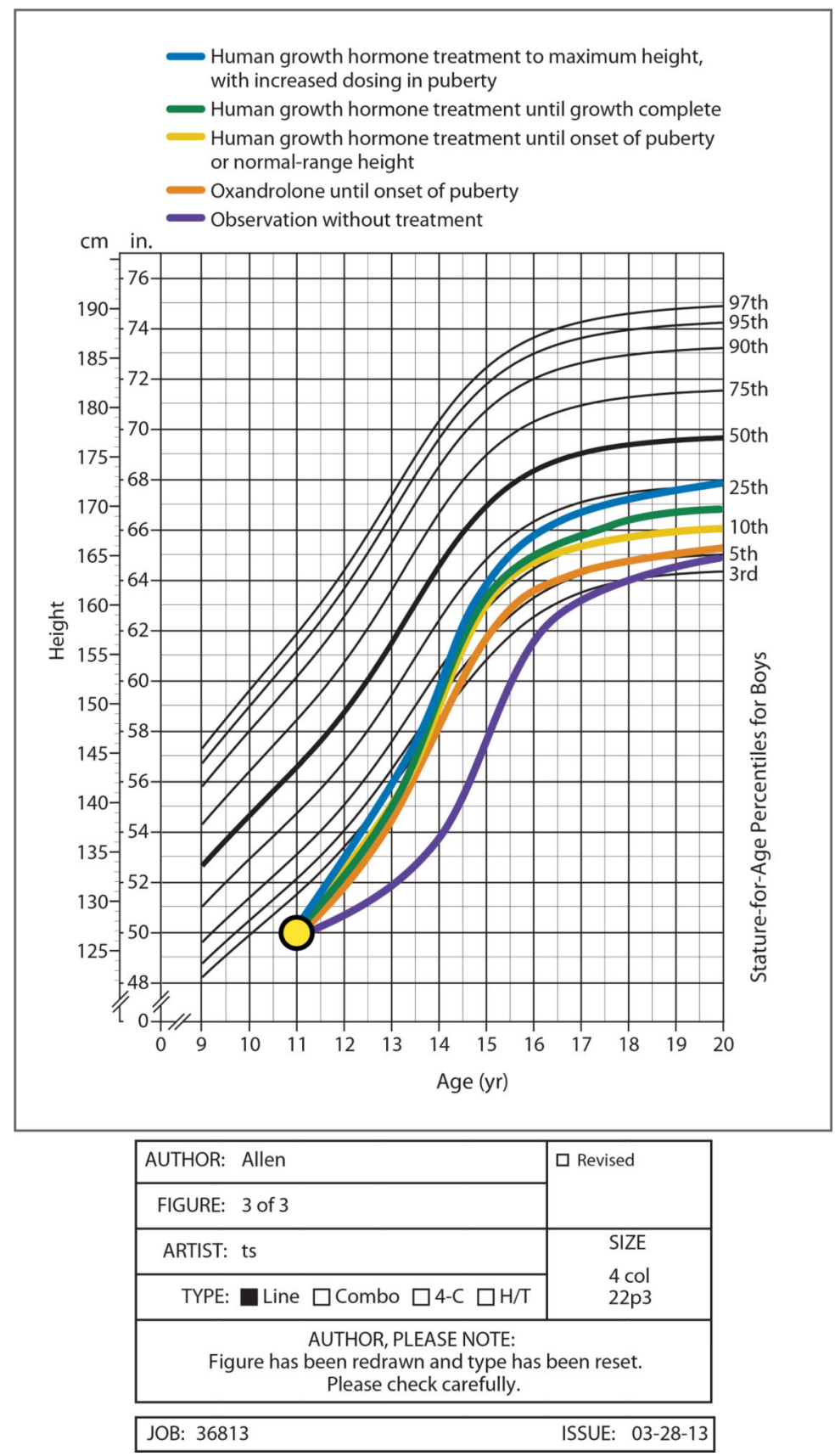

Figure 3.

Illustration of approximate projections ( \pm 1.3 inches based on Bayley Pinneau adult height predictions at 11 years of age with bone age of 9) ${ }^{1}$ for growth trajectory and adult height for various short stature treatments based on published reports of their effects

$*=$ assuming increase in growth rate to $\sim 8 \mathrm{~cm} /$ year until onset of puberty ${ }^{24}$

$* *$ assuming average reported increment in height gain for ISS $+\sim 1 \mathrm{~cm} /$ year of treatment. ${ }^{3,4}$

$* * *$ = assuming normal pubertal growth after cessation of hGH at onset of puberty (and thus no significant difference from more prolonged standard dose hGH therapy). 
**** =assuming additional increment of $3.6 \mathrm{~cm}$ of height (compared to standard-dose hGH therapy) due to 3 years of high-dose $(0.7 \mathrm{mg} / \mathrm{kg} / \mathrm{wk}) \mathrm{hGH}^{34}$. 


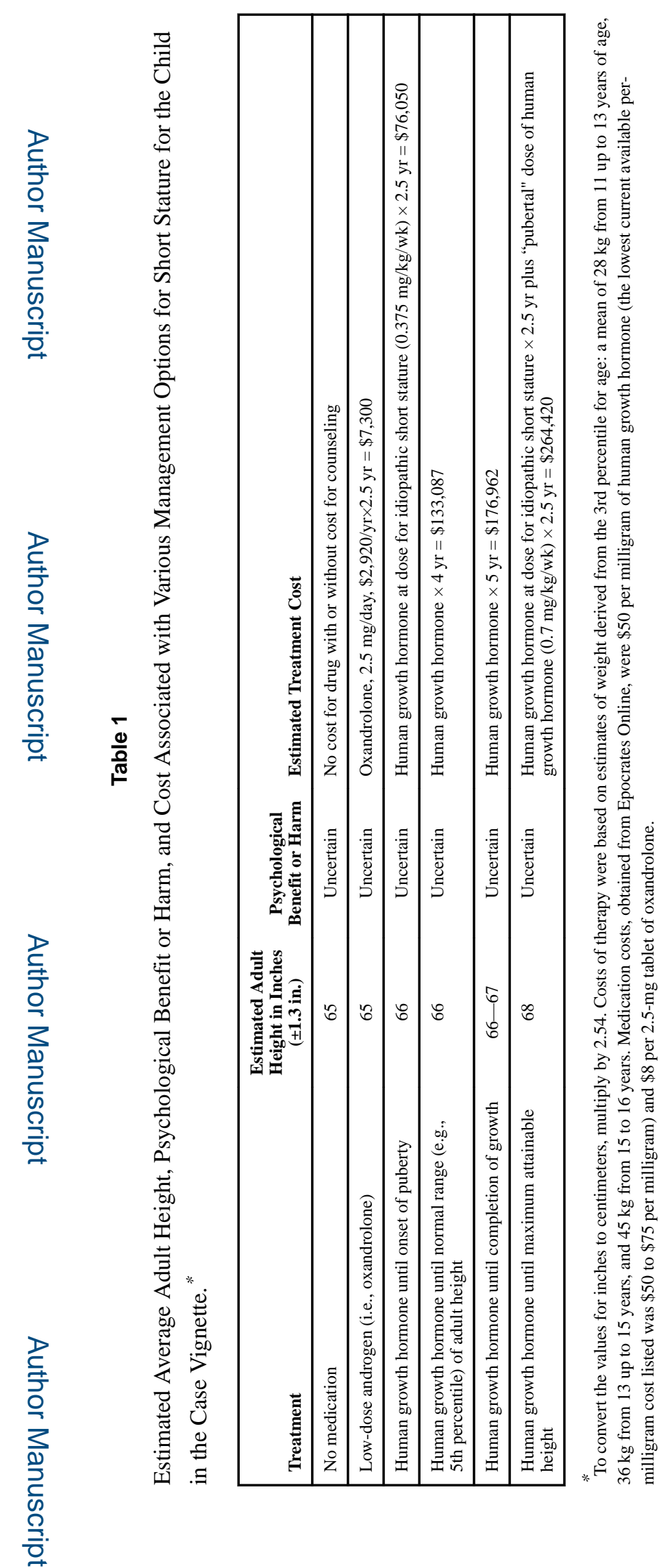

N Engl J Med. Author manuscript; available in PMC 2018 January 04. 